\title{
Carcinoma renal de células claras sincrónico con linfoma no hodgkiniano de fenotipo B de tipo MALT
}

\section{Renal synchronous carcinoma of clear cells with non-hodgkin lymphoma of phenotype $b$ of type MALT}

\section{Sr. Director:}

Presentamos el caso de un hombre de 71 años con antecedentes personales de fumador, EPOC y diabetes mellitus en tratamiento. Por hematuria macroscópica acudió al servicio de urgencias del centro y quedó ingresado para estudio. Se le realizaron las siguientes pruebas complementarias:

- Hematimetría y bioquímica general: sin alteraciones.

- Ecografía abdominal: masa sólida hiperecogénica de $3,6 \times 4,2 \mathrm{~cm}$, localizada en el polo inferior del riñón izquierdo.

- TAC de tórax: sin alteraciones.

- TAC de abdomen: formación de densidad de partes blandas en el polo inferior del riñón izquierdo, de bordes lobulados y bien definidos, ligeramente heterogénea, de unos $4 \mathrm{~cm}$, compatible con neoformación.

El 16-02-2007 se realizó nefrectomía radical izquierda por vía laparoscópica, transcurriendo el postoperatorio sin alteraciones.

En la anatomía patológica se identificaron macroscópicamente dos formaciones nodulares, una en cada polo. Microscópicamente, la formación nodular del polo inferior se correspondió con un carcinoma de células claras, grado 2 de Fuhrman (fig. 1). La formación del polo superior se caracterizaba por una densa proliferación linfoide atípica, de talla pequeña y media, constituida por células de aspecto centrocítico, células plasmocitoides y células plasmáticas con presencia ocasional de lesiones linfoepiteliales y de folículos linfoides de tipo reactivo (fig. 2). En el estudio inmunohistoquímico, dicha población linfocitaria mostró positividad para CD20 y CD79a y negatividad para CD5, CD23, CD43, CD10, bcl-2, bcl-6 y ciclina D1.

El diagnóstico anatomopatológico fue de carcinoma renal de células claras en el polo inferior sincrónico con linfoma no hodgkiniano de fenotipo B de bajo grado tipo MALT en el polo superior. Estadios ib y IE, respectivamente.

El linfoma renal primario es una neoplasia muy poco frecuente (1\%), siendo el primer caso publicado por Knoepp ${ }^{1}$. Entre estos, el de fenotipo B tipo MALT es extremadamente raro $^{2}$ y fue descrito por primera vez por Pelstring et $\mathrm{al}^{2}$.

La histogénesis del linfoma MALT en el riñón es poco conocida, aunque, como en otros órganos, podría relacionarse con respuestas a procesos inflamatorios crónicos o autoinmunes que actuarían como desencadenantes. Sin embargo, es motivo de discusión y no todos los autores están conformes cuando del riñón se habla ${ }^{3}$.

En el caso que presentamos, no se evidenciaron procesos inflamatorios de tipo crónico ni se han descubierto datos clínicos o analíticos que reflejen alteraciones de tipo inmunitario.

Por otra parte, para el diagnóstico de linfoma renal primario es preciso descartar clínicamente procesos linfoproliferativos en otros órganos ${ }^{4}$, cosa que se hizo en el estudio de extensión practicado al paciente.

El diagnóstico es anatomopatológico y suele realizarse tras nefrectomía, ya que ni por la clínica ni por las pruebas de imagen se puede diferenciar de otros tumores renales.

El linfoma B tipo MALT renal primario tiene, por lo general, un pronóstico favorable tras la cirugía, ya que suelen diagnosticarse en fase precoz (I-II). Es conocido que el factor pronóstico más importante para supervivencia libre de enfermedad y supervivencia global es el estadio. Así, en el trabajo de Papaxoinis et $\mathrm{al}^{5}$, la supervivencia libre de

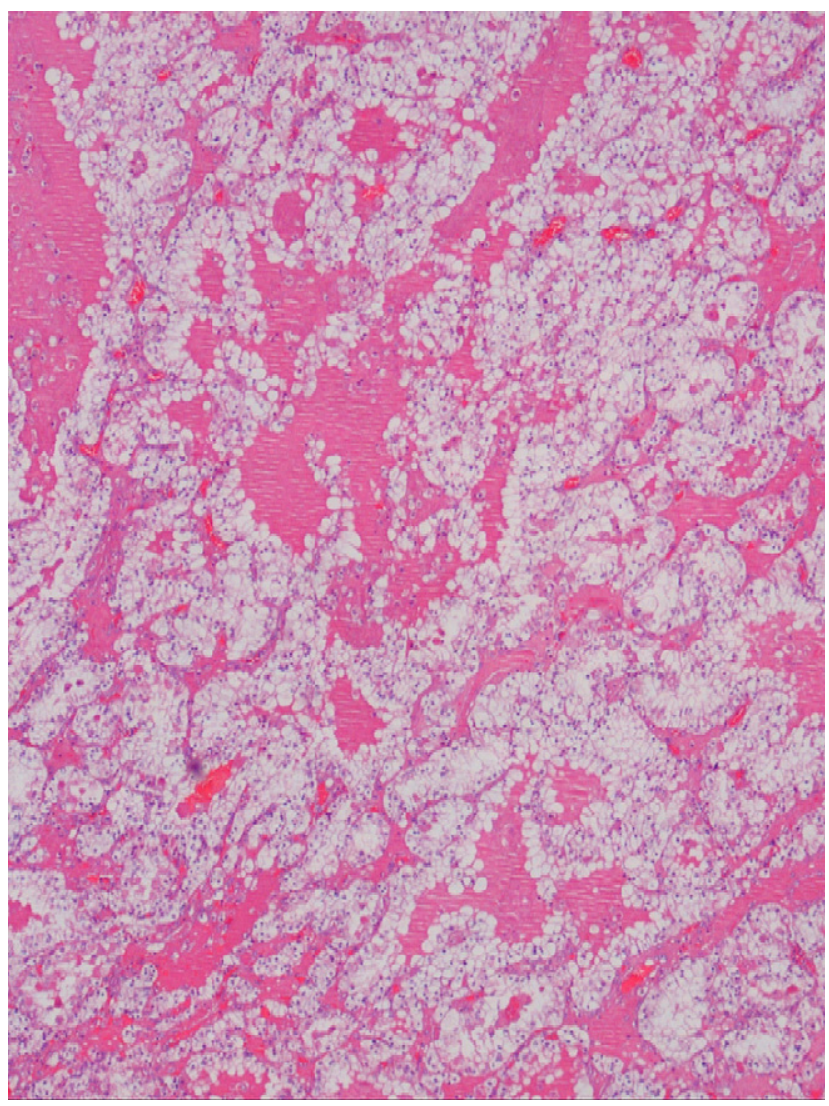

Figura 1 - Proliferación celular atípica de estirpe epitelial de patrón tubular y quístico con células amplias de citoplasma claro y núcleo de tamaño medio con presencia nucleolar. Carcinoma renal de células claras (grado il de Fuhrman). 


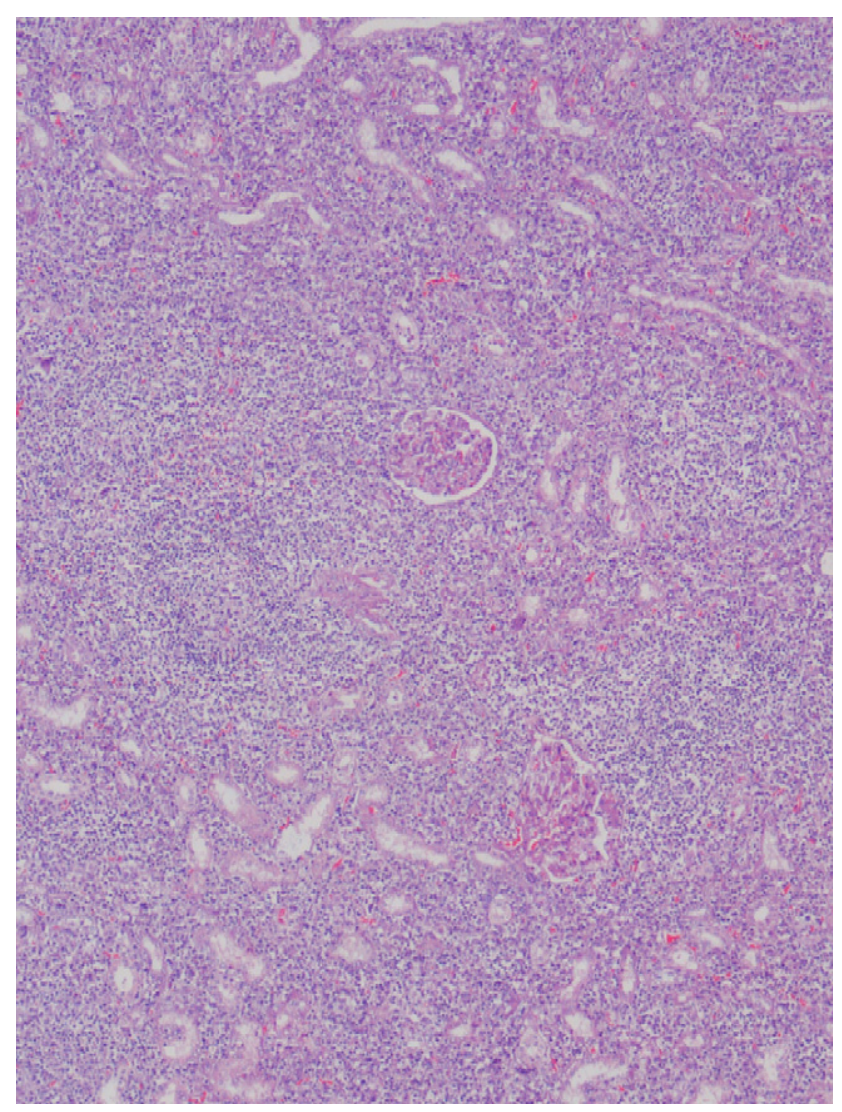

Figura 2 - Amplia y densa población linfoide atípica con elementos de talla pequeña y media que alterna con frecuentes folículos linfoides reactivos y células plasmáticas. Linfoma no hodgkiniano de fenotipo B tipo MALT.

enfermedad a 5 años fue del $67 \%$ en estadios I-II frente al 13\% en estadios III-IV. Asimismo, la supervivencia global a 5 años fue del 91 frente al 51\%, respectivamente.

En nuestro caso, el estadio fue IE, por lo que al coexistir con una neoplasia epitelial de células claras, el pronóstico del paciente dependerá, fundamentalmente, de esta última.

En cuanto al tratamiento del carcinoma renal localizado y del linfoma MALT renal primario, parece existir unanimidad en cuanto a que la nefrectomía es el método de elección. En la serie de Kato et $\mathrm{al}^{6}$ los cinco casos fueron nefrectomizados y solo uno se siguió de quimioterapia complementaria.

Por otro lado, no está definido ni el régimen más activo ni el momento de su administración. En el trabajo de Raderer et $\mathrm{al}^{7}$, de los 26 pacientes con linfoma MALT recidivados de diversas localizaciones, 15 recibieron rituzimab más ciclofosfamida, adriamicina, vincristina y prednisona y a los 11 restantes se les administró el mismo régimen sustituyendo la adriamicina por mitoxantrone, ya que tenían edad superior a 65 años o padecían comorbilidad cardíaca. Hubo el $77 \%$ de respuestas completas y el $23 \%$ de respuestas parciales, concluyendo los autores la alta actividad de ambos regímenes en pacientes con linfoma MALT recidivados.

En el trabajo de Wöhrer et $\mathrm{al}^{8}$ los autores concluyen que en pacientes con linfoma MALT estadios III-IV (10 extragástricos), la combinación de mitoxantrone, clorambucil y prednisona es efectiva y bien tolerada, independientemente de su localización.

En el caso que presentamos, al tratarse de un estadio i para ambas neoplasias, se optó por nefrectomía y seguimiento periódico sin emplear ningún tratamiento adyuvante, ni local ni sistémico.

B I B L I O G R A F Í A

1. Knoepp LF. Lymphosarcoma of the kidney. Surgery. 1956;39:510-4.

2. Pelsting RJ, Essell JH, Kurtin PJ, Cohen AR, Banks PM. Diversity of organ site involvement among malignant lymphoma of mucosa-associated lymphoid tissues. Am J Clin Pathol. 1991; 96:738-45.

3. Qiu L, Unger PD. Low brade mucosa associated lymphoid tissue lymphoma involving the kidney. Report of 3 cases and review of the literature. Arch Pathol Lab Med. 2006;130: 86-9.

4. Dobkin SF, Brem AS, Caldemone AA. Primary renal lymphoma. J Urol. 1991;146:1588-990.

5. Papaxoinis G, Fountzilas G, Rontogianni D, Dimopoulos MA, Pavlidis N, Tsatalas C, et al. Low-grade mucosa-associated lymphoid tissue lymphoma: A retrospective analysis of 97 patients by the Hellenic Cooperative Oncology Group (HeCOG). Ann Oncol. 2008;19:780-6.

6. Kato Y, Hasegawa M, Numasato S, Monma N, Fujioka T. Primary mucosa-associated lymphoid tissue-type lymphoma arising in the kidney. Int J Urol. 2008;15:90-2.

7. Raderer M, Wohrer S, Streubel B, Drach J, Jager U, Turetschek K, et al. Activity of rituximab plus cyclophosphamide, doxorubicin/mitoxantrone, vincristine and prednisone in patients with relapsed MALT lymphoma. Oncology. 2006;70: 411-7.

8. Wöhrer S, Drach J, Hejna M, Schethauer W, Dirisamer A, Püspök A, et al. Treatment of extranodal marginal zona B-cell lymphoma of mucosa-associated lymphoid tissue (MALT lymphoma) with mitoxantrone, chlorambucil and prednisone (MCP). Ann Oncol. 2003;14:1758-61.

\section{J.A. Contreras-Ibáñez ${ }^{a, *}$, L. Díaz-Gómezb y P. Muriel-Cueto ${ }^{c}$}

${ }^{a}$ Servicio de Oncología Médica, Hospital Universitario Puerta del Mar, Cádiz, España

bervicio de Oncología Radioterápica, Hospital Universitario Puerta del Mar, Cádiz, España

'Servicio de Anatomía Patológica, Hospital Universitario Puerta del Mar, Cádiz, España

*Autor para correspondencia.

Correo electrónico: josea.contreras.sspa@juntadeandalucia.es (J.A. Contreras-Ibáñez). 